\begin{tabular}{|c|}
\hline 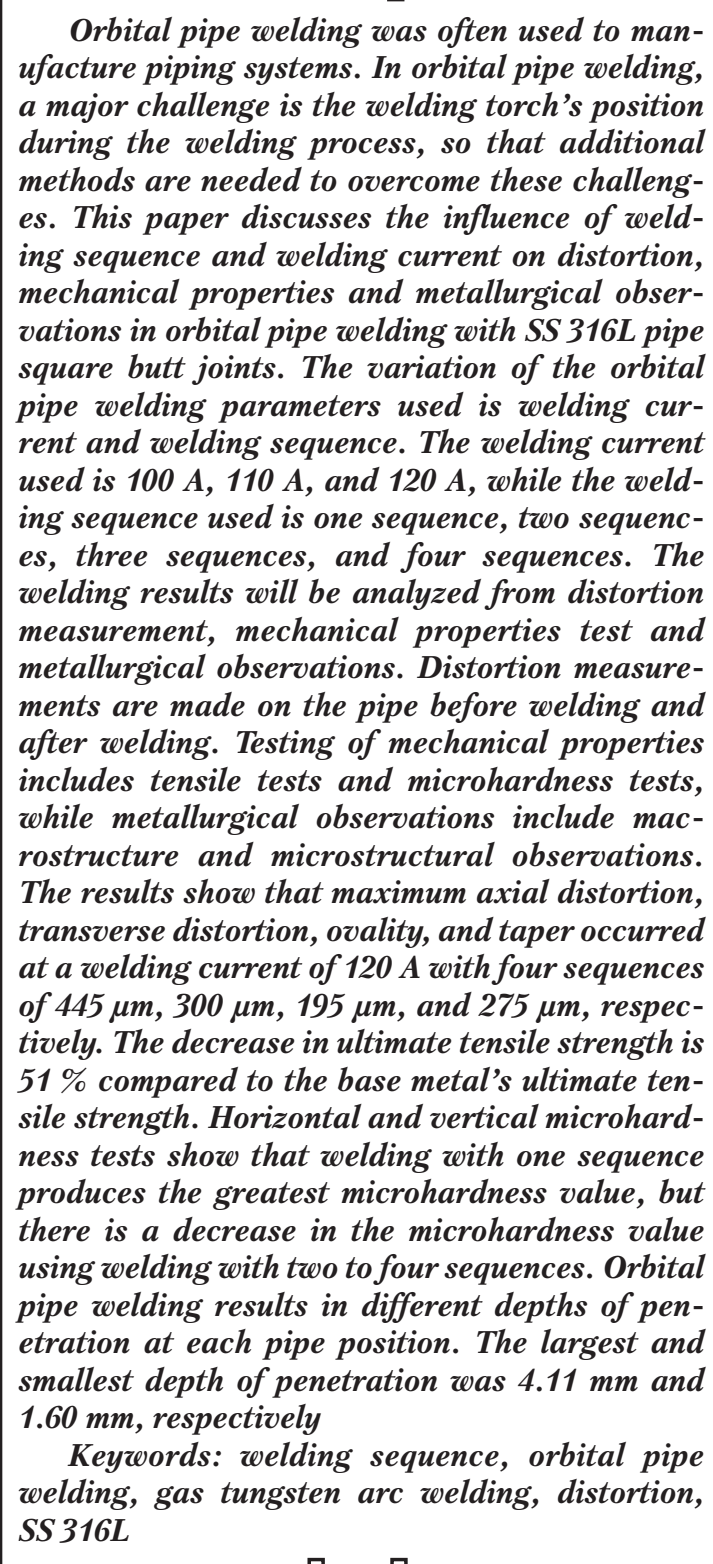 \\
\hline
\end{tabular}

UDC 621

DOI: 10.15587/1729-4061.2021.228161

\section{EFFECT OF WELDING SEQUENCE AND WELDING CURRENT ON DISTORTION, MECHANICAL PROPERTIES AND METALLURGICAL OBSERVATIONS OF ORBITAL PIPE WELDING ON SS 316L}

\author{
Agus Widyianto \\ Postgraduate student* \\ E-mail: widyiantoagus@gmail.com \\ Ario Sunar Baskoro \\ Doctorate, Professor* \\ E-mail: ario@eng.ui.ac.id
}

Gandjar Kiswanto

Doctorate, Professor*

E-mail: gandjar_kiswanto@eng.ui.ac.id

Muhamad Fathin Ginanjar Ganeswara

Bachelor*

E-mail: Muhamadfathin48@yahoo.com *Department of Mechanical Engineering Universitas Indonesia Kampus Baru UI Depok, Indonesia, 16424
Received date 25.02.2021 Accepted date 07.04.2021 Published date 30.04.2021
How to Cite: Widyianto, A., Baskoro, A. S., Kiswanto, G., Ganeswara, M. F. G. (2021). Effect of welding sequence and welding current on distortion, mechanical properties and metallurgical of orbital pipe welding on SS 316L. Eastern-European Journal of Enterprise Technologies, 2 (12 (110)), 22-31. doi: https://doi.org/10.15587/1729-4061.2021.228161

\section{Introduction}

Welding plays an essential role in construction or manufacturing [1]. This makes welding a vital part of the industry. Along with the times, the existing welding also developed and updated technology in the field of welding. This technological development aims to improve the quality of welding results.

Gas Tungsten Arc Welding (GTAW) is a type of electric arc welding widely used in industry because it can combine various types of metal materials, both similar or dissimilar metal joints, with high weld quality results. The welding metal melting process occurs due to the influence of heat from an electric arc that arises between the tungsten electrode (non-consumable) and the workpiece. The electric arc area will be shielded from the atmosphere by inactive gases such as argon flowing through the blowtorch's nozzle.
GTAW welds can be operated without filler metal or known as autogenous welds [2], to combine thin materials with a thickness of less than or equal to $3 \mathrm{~mm}[3,4]$. Whereas filler is used when joining material with a thickness of more than $3 \mathrm{~mm}$. Welding with thick material generally requires preparation of the joint and several welding phases to fill the joint gap. The material being welded can be in the form of plates or pipes with various types of joints.

A pipe is one of several materials used for a long time for transportation, such as water, oil and gas. This is an economical form of transportation compared to other means of transportation. Nowadays, pipes are widely used to transport goods over long distances. This requires pipe construction and pipe connection to increase productivity, one of which is pipe welding [5]. Pipe welding is widely used in almost every engineering application, for example, the oil 
and gas industry, the automotive industry, nuclear and thermal power plants and others. Thus, pipe welding indirectly affects product quality and safety [6, 7].

The increase in natural gas use, which is predicted in the next 20 years, will affect the existing oil and gas industry so that these industries demand a wider use of pipe welding [8]. With the increasing use of pipe welding, a pipe is needed to transmit the gas and this requires a significant investment. So it is necessary to have a pipe that can transmit gas with high operating pressure and the selection of high strength materials and has higher toughness and ductility. But what is expected in building this pipeline transmission system has a low cost.

\section{Literature review and problem statement}

Pipes can be joined by three pipe welding mechanisms, including stationary pipe welding [9], orbital pipe welding [10] and pipe welding using the friction method [11]. Orbital pipe welding is a welding mechanism that is often used to manufacture piping systems. In orbital pipe welding, a major challenge is the welding torch's position during the welding process. As shown in Fig. 1, pipe welding is divided into four positions. The positions are flat $\left(0^{\circ}\right)$, descendant vertical $\left(90^{\circ}\right)$, overhead $\left(180^{\circ}\right)$ and ascendant vertical $\left(270^{\circ}\right)$ [1]. In each of the optimal parameters of the welding torch has to do with the resulting weld pool.

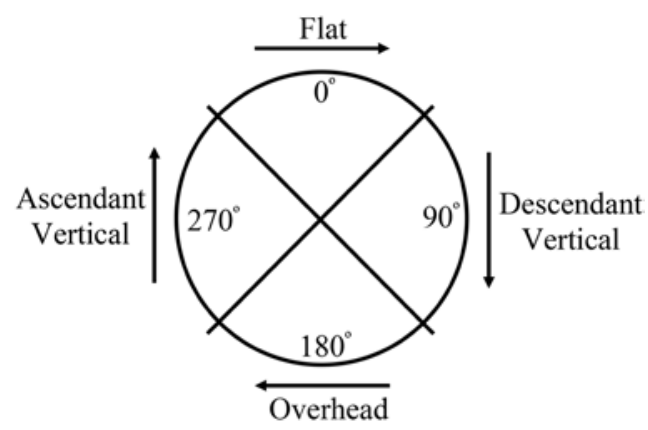

Fig. 1. Pipe position in orbital pipe welding

The problems that often arise in pipe welding are the depth of penetration, the weld bead's width, and unstable distortion, especially in orbital pipe welding. Because of the depth of weld penetration, the weld bead's width and the amount of distortion are important factors in determining the weld's quality. Besides, this will affect the mechanical properties and microstructure. Increasing the penetration depth and width of the weld bead in the GTAW welding process can be done by increasing the weld current or slowing the welding speed. However, an increase in weld current, a decrease in speed, or an increase in the welding sequence can result in increased distortion due to high heat input and temperature $[7,12]$.

Several researchers previously investigated the effect of welding sequence on distortion in materials such as SS 304 plate [13], aluminum alloy 6061-T6 [14], octagonal pipe plate structure [14] and AISI 304 pipe [7]. The welding current has a greater influence on the distortion than the welding speed [1]. The finite element method was used to determine the effect of the welding sequence on pipe joint distortion [7]. There are nine variations of the welding sequence with different welding segments. The results showed that the increase in the number of welding sequences at the pipe joints decreased the welding distortion and at $4 \mathrm{~A}$ welding sequences, the greatest distortion occurred. The Taguchi method can be applied to find the optimal welding parameters with the lowest distortion [15]. The welding method using pulsed currents has been shown to reduce the distortion that occurs in the material [16].

The paper [7] examines the effect of welding sequence on distortion using simulation and experimental approaches. The distortion measurement results in a simulation will be validated by using experimental data. There are 8 variations of the welding sequence. Apart from distortion in pipes, other things need to be investigated, among others, in terms of mechanical properties and metallurgical observations. This also affects the quality of the weld, especially in pipe welding. Therefore, it is necessary to do more research related to the effect of welding sequence parameters on distortion, mechanical properties and metallurgical observations in orbital pipe welding. One type of material that is often used in piping systems is stainless steel pipes, so in this study we will use SS 316L stainless steel pipes.

\section{The aim and objectives of the study}

This study aims to investigate the effect of the welding sequence and welding current on SS316L pipes using the orbital pipe welding method.

To achieve this aim, the following objectives are accomplished:

- to investigate the amount of distortion produced after the welding process for various welding sequences and welding currents;

- to investigate the ultimate tensile strength and microhardness value of the weld for various welding sequences and welding currents;

- to observe the macrostructure and microstructure welds results for various welding sequences and welding currents

\section{Material and method of experiment}

In this study, the material used was stainless steel pipe type 316L (SS 316L). The pipe diameter to be welded is $114.3 \mathrm{~mm}$ with a thickness of $3 \mathrm{~mm}$ and a length of $110 \mathrm{~mm}$. The pipe is joined without using added material (autogenous) with a square butt joint (Fig. 2).

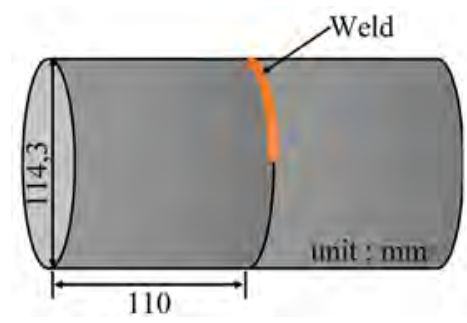

Fig. 2. Schematic illustration of specimen dimensions

The optical emission spectrometer (OES) test was used to determine the chemical composition of SS 316L. Before 
welding, the material is sanded using sandpaper from a roughness of 80 to 400 , after which it is cleaned with acetone solutions.

The type of welding used in this research is Gas Tungsten Arc Welding (GTAW) with square butt joints without added materials. This study's welding machine was a TIG Miller welding machine, Dynasty 210 DX AC/DC type. Pure argon gas $(99.99 \%)$ was used to protect the pipe's outer and inner parts from oxidation with flow rates of $11 \mathrm{~L} / \mathrm{min}$ and $5 \mathrm{~L} / \mathrm{min}$, respectively. Fig. 3 shows a schematic of the orbital pipe welding process.

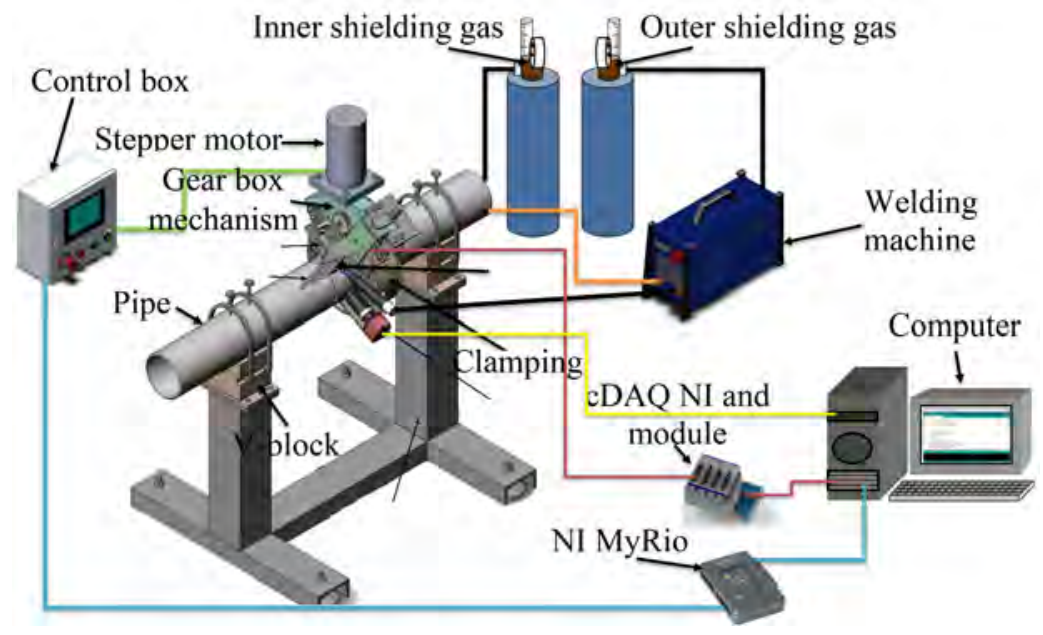

Fig. 3. Schematic illustration of the orbital pipe welding process

The welding position applied in this study is the $5 \mathrm{G}$ position, where the pipe is placed horizontally in a fixed state while the welding torch rotates around the pipe (orbital). Then the welding method uses the welding sequence method on the pipe (Fig. 4, $a-d$ ). There are four variations of the welding sequence used to weld pipes. Pipe welding is carried out from one sequence (1 welding process) to four sequences (4 welding processes). The second welding process waits until the material reaches room temperature and for the third and fourth welding processes. Welding starts at an angle of the pipe $330^{\circ}$ and rotates clockwise until the welding torch returns to the starting position. The welding parameters used in this study are shown in Table 1.

Table 1

Orbital pipe welding parameters

\begin{tabular}{|c|c|}
\hline Parameter & Value \\
\hline & a) $100 \mathrm{~A}$ \\
Welding currents & b) $110 \mathrm{~A}$ \\
& c) $120 \mathrm{~A}$ \\
\hline & a) 1 sequence \\
Welding sequences & b) 2 sequences \\
& c) 3 sequences \\
& d) 4 sequences \\
\hline Welding speed & 1.4 mm/s \\
\hline Electrode type & EWCe-2 with tip grey \\
\hline Diameter of electrode & $2.4 \mathrm{~mm}$ \\
\hline Electrode distance to the & $3 \mathrm{~mm}$ \\
workpiece &
\end{tabular}
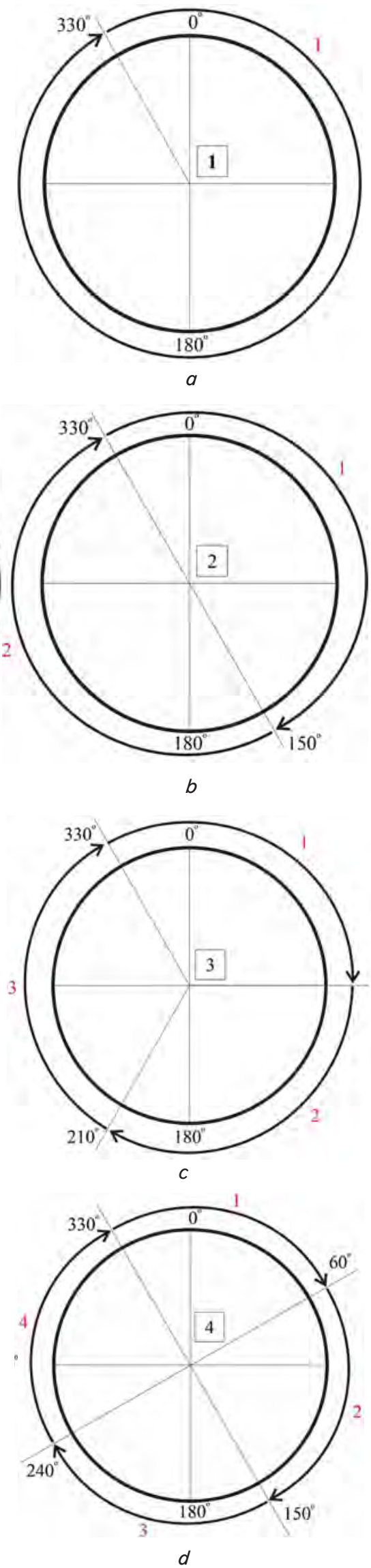

Fig. 4. Orbital pipe welding sequence: $a-1$ sequence; $b-2$ sequences; $c-3$ sequences; $d-4$ sequences 
The difference in pipe diameter before being welded and after being welded is the amount of distortion that occurs in a pipe. There are three segments of the pipe diameter measurement of $15 \mathrm{~mm}, 30 \mathrm{~mm}$ and $50 \mathrm{~mm}$ from the center point of the weld in the axial direction and the transverse direction of the pipe as shown in Fig. 5, $b$. An outer micrometer with the precision of $0.01 \mathrm{~mm}$ was used to measure the pipe diameter in each pipe segment and direction. There were several types of deformations in the pipe after being welded, such as axial and transverse distortion, ovality, and taper (Fig. 5, a).
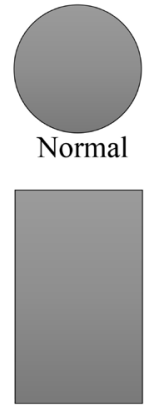

Normal

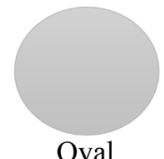

Oval

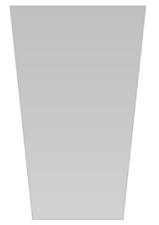

Tapers $a$

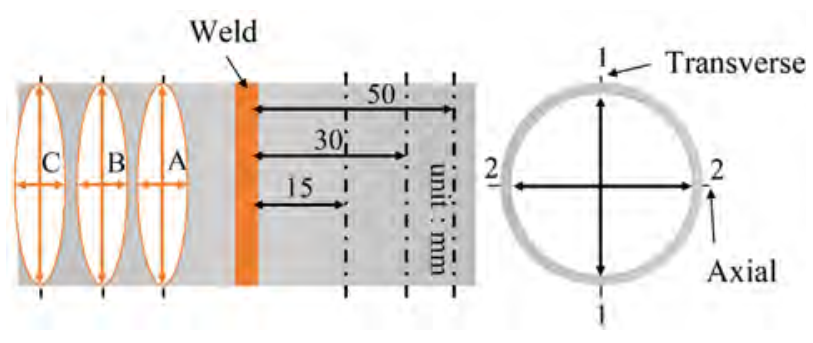

$b$

Fig. 5. Schematic of: $a$ - distortion that occurs in pipes; $b$ - measurement of distortion in pipes

The values of transverse distortion (TD) and axial distortion (AD) can be found using Equations (1) and (2) [1]:

- transverse distortion

$(T D)=D_{a 1}-D_{b 1} ;$

- axial distortion

$(A D)=D_{a 2}-D_{b 2}$,

where $D_{a 1}, D_{a 2}$ are the pipe diameters after being welded while $D_{b 1}, D_{b 2}$ are the pipe diameters before being welded in the transverse and axial direction.

Apart from looking at the pipe diameter change (transverse distortion and axial distortion), pipe ovality can also be calculated in each section of the pipe. If the calculation results for each part of the pipe are not the same, the pipe diameter has become oval. A taper is where the pipe's diameter at one end and the end of the pipe does not equal the axial or transverse direction of the pipe. Calculation of the pipe invalidity and inclination can be calculated using (3), (4) [1]:

Ovality $=A D-T D$,
Tapers $=A D \max -A D \min$ atau $T D \max -T D \min$,

where $A D \max , T D \max$ are the maximum axial distortion and transverse distortion while $A D \mathrm{~min}, T D \mathrm{~min}$ are the minimum axial distortion and transverse distortion.

Testing of mechanical properties includes tensile tests and microhardness tests. (A\&D Company, Tokyo, Japan) is used for tensile testing with a constant cross-head speed of $5 \mathrm{~mm} / \mathrm{min}$. Fig. $6, a$ shows the dimensions of the tensile test specimen with the ASTM E-8M standard. The (Mitutoyo Asia Pacific Pte. Ltd., Japan) is used to measure the microhardness with a load of $500 \mathrm{~g}$ for 15 seconds. The indentations were made on the horizontal distribution (11 points) and vertical distribution ( 7 points) with a distance between indentations of $500 \mu \mathrm{m}$ and $250 \mu \mathrm{m}$, respectively (Fig. 6, $b$ ).

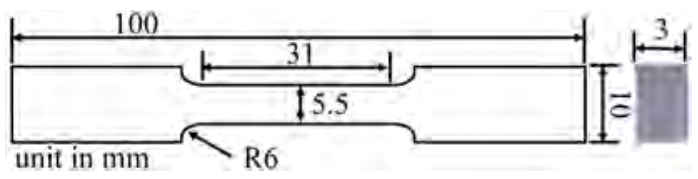

$a$

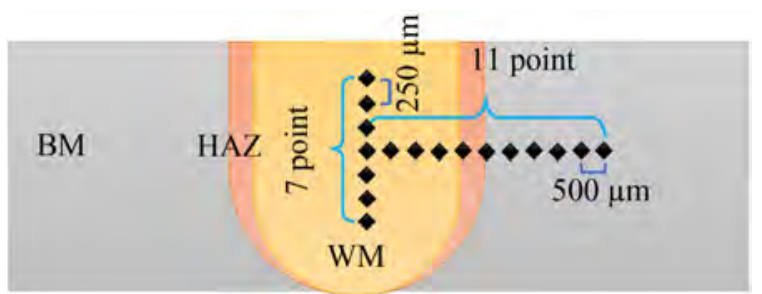

$b$

Fig. 6. Schematic dimension of: $a$ - tensile test specimen; $b-$ microhardness test specimen

Metallurgical observations include macrostructure and microstructure observations. Specimens were cut in cross-section at pipe positions $0^{\circ}, 90^{\circ}, 180^{\circ}$ and $270^{\circ}$. Preparation of specimens for metallurgical testing involves sanding the specimens with wet sandpapers of the roughness of 240,600, 800 and 1,500. Then the specimens are polished with a mixture of titanium (IV) oxide and ethanol. The combination of $5 \mathrm{ml}$ of $\mathrm{HNO}_{3}, 5 \mathrm{ml}$ of $\mathrm{HCl}, 1 \mathrm{~g}$ of picric acid and $200 \mathrm{ml}$ of ethanol was used for etching the microstructural test specimens. Macrostructure observations were carried out using a digital microscope (Dino-Lite) to measure the depth of penetration. Olympus GX51 microscope was used to observe microstructure and evaluate segregation in Base Metal (BM), Heat Affected Zone (HAZ), and Weld Metal (WM).

\section{Results of the experiment}

\section{1. Results of distortion}

The distortion calculation in the pipe is the difference between the pipe diameter measurement before being welded and after being welded. Fig. 7, $a$ shows the pipe surface profile before welding with three measuring distances from the weld center. Fig. $7, b$ is a pipe surface 
profile after welding with three measuring distances from the weld center.

Fig. $8, a-c$ show the maximum distortion, ovality and taper at welding currents of $100 \mathrm{~A}, 110 \mathrm{~A}$ and $120 \mathrm{~A}$, respectively. There was a decreasing maximum axial distortion, transverse distortion, ovality and taper that occurred in one sequence to two sequences. Furthermore, the maximum axial and transverse distortion, ovality and taper will increase in four sequences. In four sequences, each welding current produces the greatest axial and transverse distortion, ovality and taper. Maximum axial distortion, transverse distortion, ovality and taper occurred at a welding current of $120 \mathrm{~A}$ with four sequences of $445 \mu \mathrm{m}$, $300 \mu \mathrm{m}, 195 \mu \mathrm{m}$ and $275 \mu \mathrm{m}$, respectively.
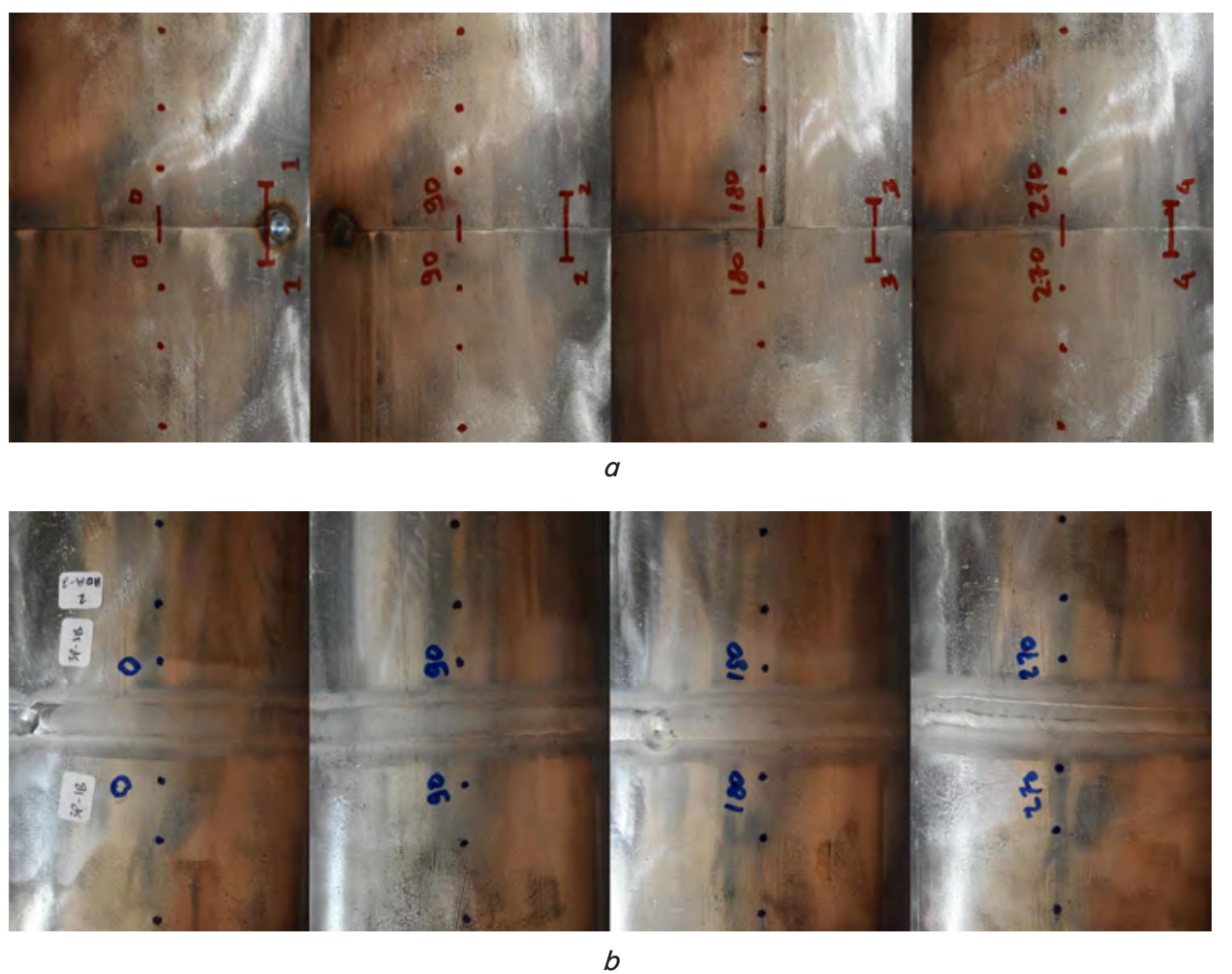

Fig. 7. Pipe surface profile: $a$ - before welding; $b$ - after welding

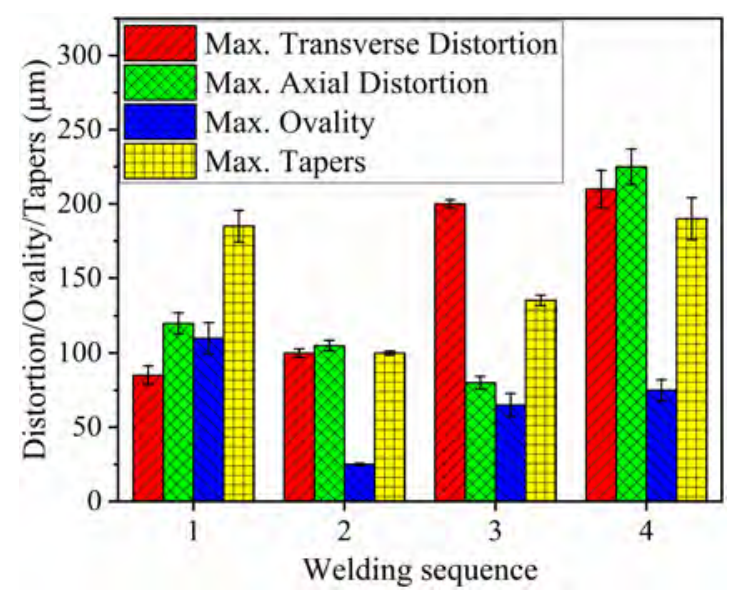

a

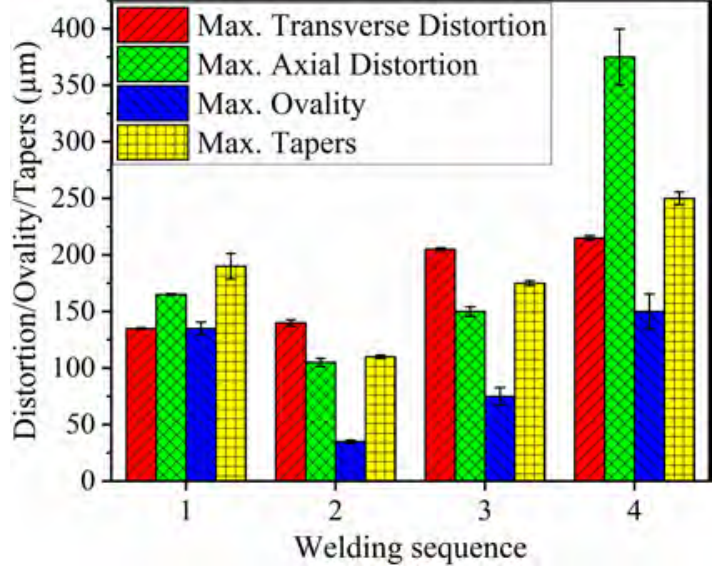

$b$

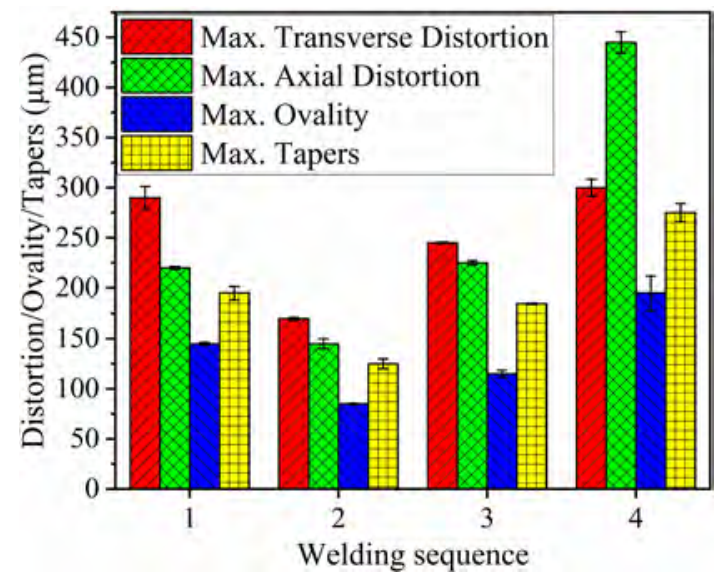

c

Fig. 8. Maximum distortion/ovality/tapers for each welding current: $a-100 \mathrm{~A} ; b-110 \mathrm{~A} ; c-120 \mathrm{~A}$ 


\section{2. Results of mechanical properties test}

Tensile test specimens were prepared at four-pipe positions with three replications. The pre-tested and post-tested tensile test specimens are shown in Fig. 9, $a, b$, respectively. Almost all of the fracture locations of the tensile test results are in the weld metal area.

The results of the ultimate tensile strength (UTS) with the variation of welding current and welding sequence

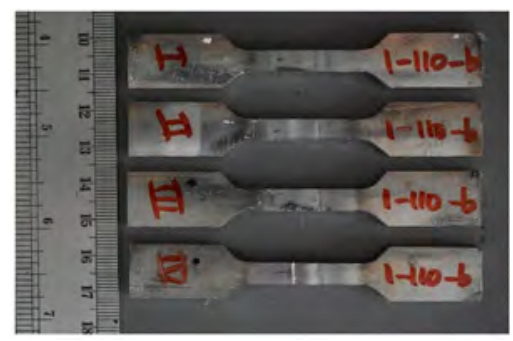

$a$ are plotted in Fig. $10, a-d$ with each pipe position $0^{\circ}, 90^{\circ}$, $180^{\circ}$ and $270^{\circ}$. Welding with one sequence and a welding current of $120 \mathrm{~A}$ produces the greatest tensile strength of $662.58 \mathrm{MPa}$ in a pipe position of $90^{\circ}$. While the smallest tensile strength is $334.09 \mathrm{MPa}$ at a pipe position of $90^{\circ}$ with two sequences and a welding current of $100 \mathrm{~A}$. The smallest and largest decreases in ultimate tensile strength against the base metal were $3 \%$ and $51 \%$, respectively.

Fig. 9. Specimens tensile test: $a$ - before test; $b$ - after test

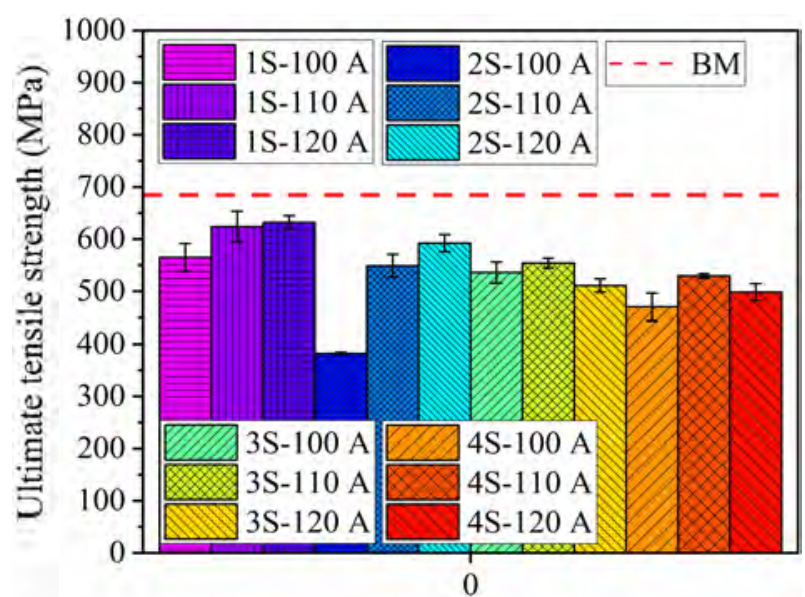

Pipe position (degree)

$a$

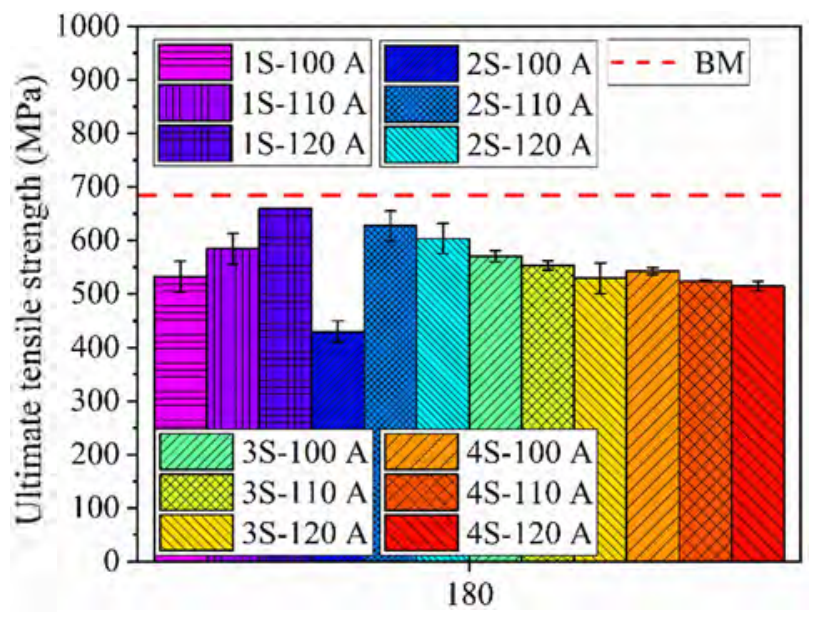

Pipe position (degree)

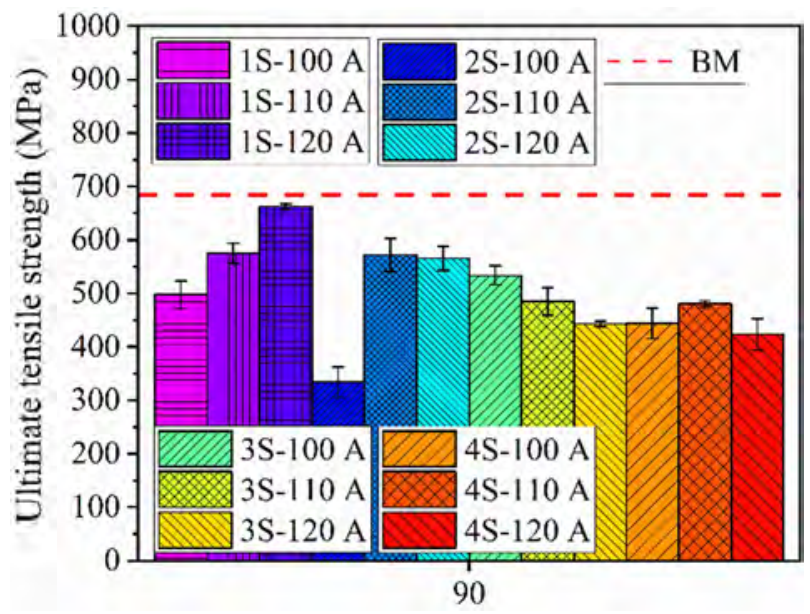

Pipe position (degree)

b

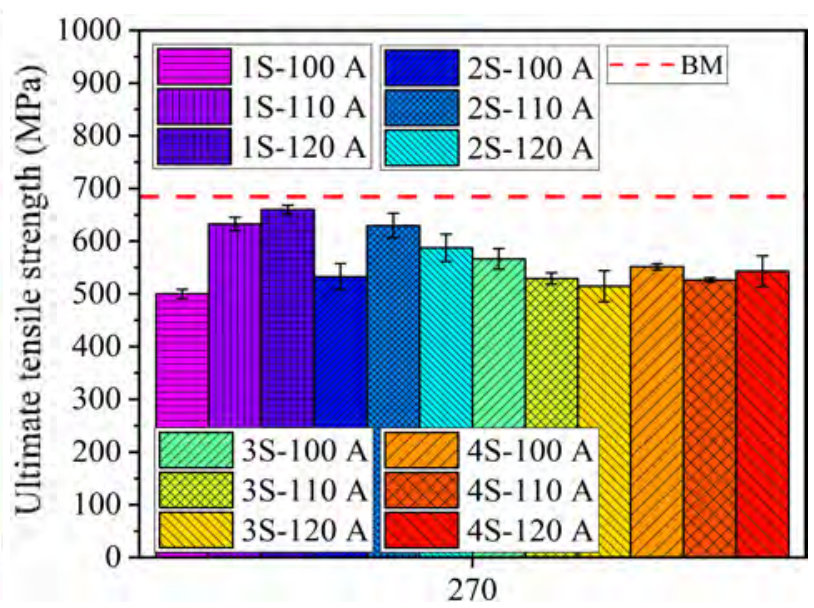

Pipe position (degree)

Fig. 10. Ultimate tensile strength for different parameters and pipe positions: $a-0^{\circ} ; b-90^{\circ} ; c-180^{\circ}$; $d-270^{\circ}$ compared to the base metal 
Vickers indentations performed a microhardness test on the metallurgical specimen. Fig. 11, $a, b$ show the microhardness values at the welding current of $110 \mathrm{~A}$ and the pipe position of $180^{\circ}$ with horizontal distribution and vertical distribution. The microhardness test points on the horizontal distribution were carried out from the WM, HAZ, to BM areas. In contrast, the microhardness testing on the vertical distribution was carried out in the WM center area. Horizontal and vertical microhardness tests show that welding with one sequence produces the greatest microhardness value, but there is a decrease in the microhardness value using welding with two to four sequences. In the horizontal distribution, the highest microhardness value occurred in one sequence of $238.1 \mathrm{HV}$, but the smallest microhardness value occurred in three sequences of $167.9 \mathrm{HV}$. Whereas in the vertical distribution, the highest microhardness value in one sequence of $242.8 \mathrm{HV}$, and the smallest microhardness value in the four sequences of $181.9 \mathrm{HV}$.

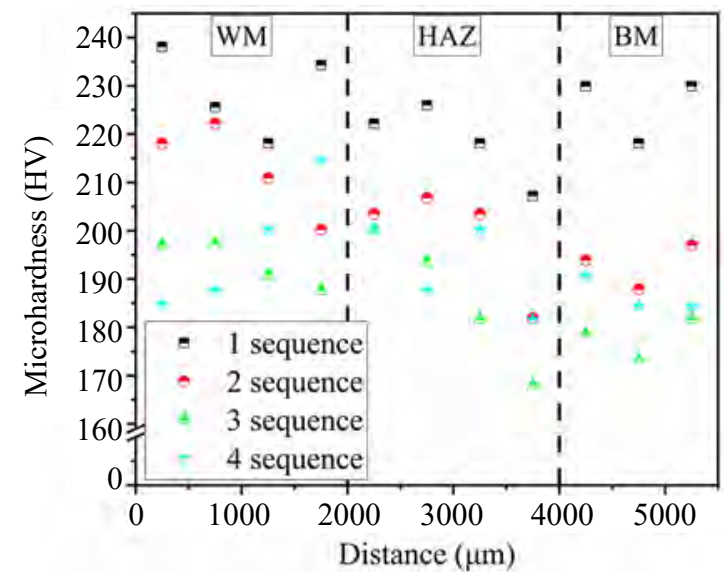

$a$

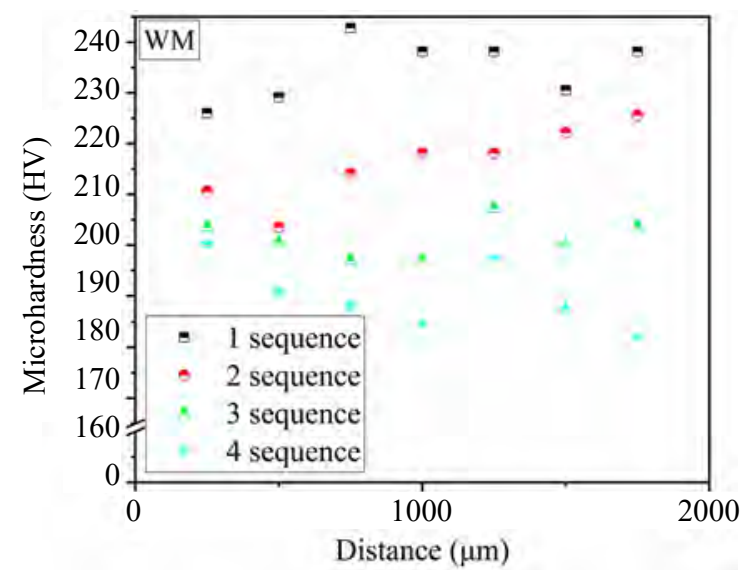

$b$

Fig. 11. Microhardness value at a welding current of $110 \mathrm{~A}$ and pipe position of $180^{\circ}$ with: $a$ - horizontal distribution; $b$ - vertical distribution

\section{3. Results of metallurgical observation}

Specimens were cut in cross-section to observe the metallurgical phenomena. Fig. 12 shows a macrostructure at a welding current of $110 \mathrm{~A}$ with different welding sequences and pipe positions. Based on macrostructural observations, it can be seen that welding with one sequence provides a deep weld penetration that penetrates the specimen. Meanwhile, adding the sequence of welding can prevent weld penetration.

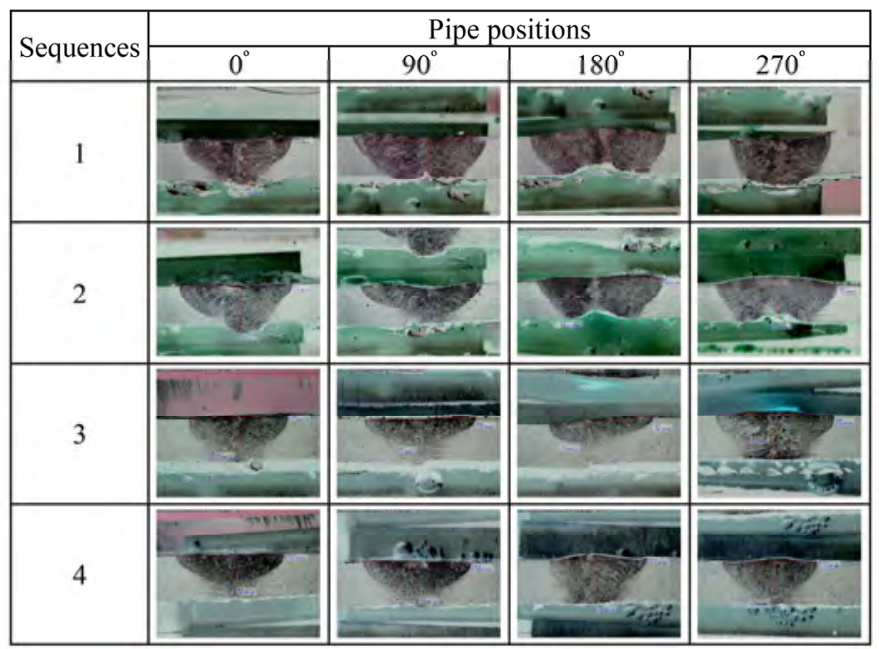

Fig. 12. Macrograph at a welding current of $110 \mathrm{~A}$ with different sequences and pipe positions

Fig. 13 shows the depth of penetration at a welding current of $110 \mathrm{~A}$ with the welding sequence and pipe position. Based on the results, one sequence has a penetration depth that exceeds the pipe thickness (penetration can penetrate the specimen) for all pipe positions. If you add the welding sequence, the penetration depth will be reduced (penetration can't penetrate the specimen) for some of the pipe positions. The largest depth of penetration in two sequences with pipe position $0^{\circ}$ was $4.11 \mathrm{~mm}$ and the smallest depth of penetration in three sequences with pipe position $180^{\circ}$ was $1.60 \mathrm{~mm}$.

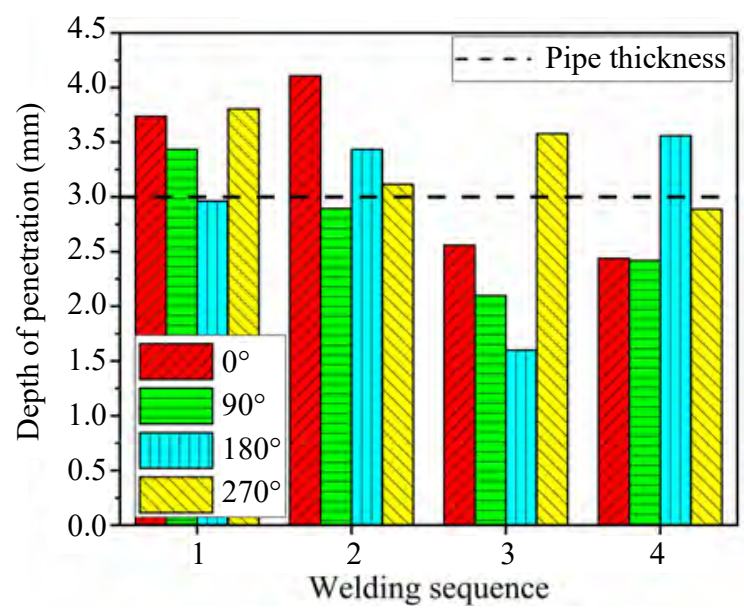

Fig. 13. Depth of penetration at a welding current of $110 \mathrm{~A}$ with a different sequences and pipe positions

Microstructural observations were made at a welding current of $110 \mathrm{~A}$, pipe position of $180^{\circ}$ with one and four sequences shown in Fig. 14, 15, respectively. Fig. 14, $a$ shows the WM-HAZ interface's microstructural results with a blue line showing Fusion Boundary (FB) at low magnification. 


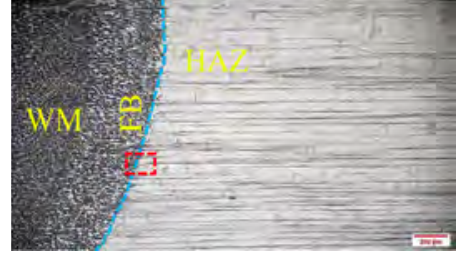

$a$

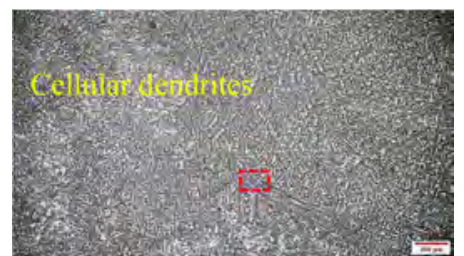

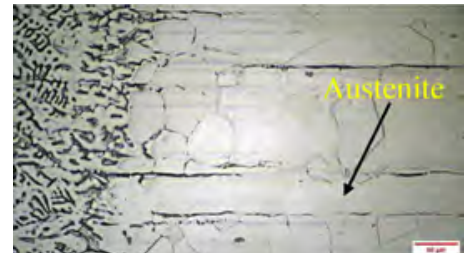

$b$

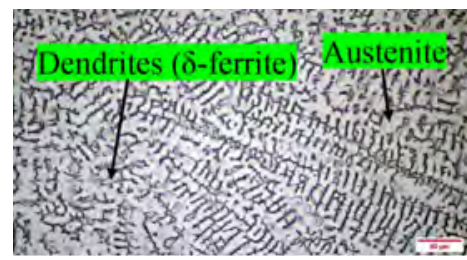

d

Fig. 14. Micrograph at a welding current of $110 \mathrm{~A}$, one sequence and pipe position of $180^{\circ}$ with: $a, c$ - low magnification; $b, d-$ high magnification

The red box shows high magnification of the $\mathrm{FB}$ and HAZ (Fig. 14, b). In the HAZ area, the austenite structure with a large grain size is visible. The microstructure observed in the middle area of the weld metal with low magnification and high magnification is shown in Fig. 14, $c, d$, respectively. In the $\mathrm{WM}$ area, the microstructure formed is cellular dendrite with fine grain size. When enlarged, the dendrite ( $\delta$-ferrite) structure extends with a small austenite structure.

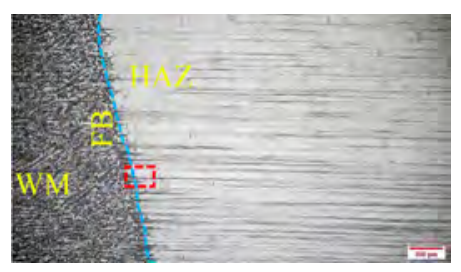

$a$

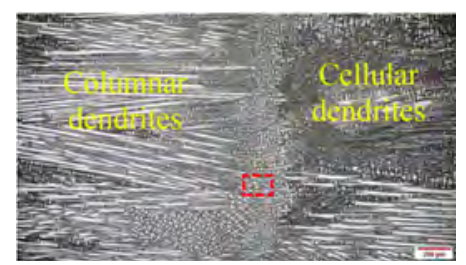

C

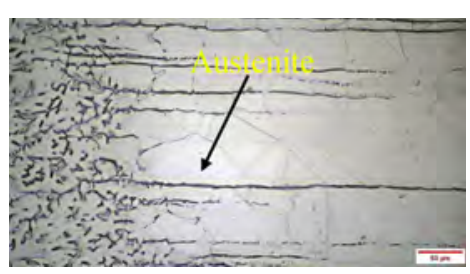

$b$

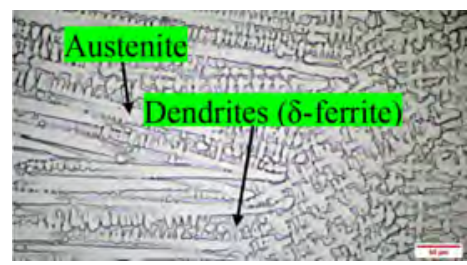

d

Fig. 15. Micrograph at a welding current of $110 \mathrm{~A}$, four sequences and pipe position of $180^{\circ}$ with: $a, c-$ low magnification; $b, d-$ high magnification

Microstructural observations on the WM - HAZ interface with low magnification are shown in Fig. 15, $a$. Almost the same as the microstructure in one sequence, there were $\mathrm{WM}, \mathrm{FB}$ and $\mathrm{HAZ}$ regions. Fig. 15, $b$ illustrates the high magnification of the red box area in Fig. 15, $a$. The austenite structure appears to have a large grain size in the HAZ region. There are two structures in the WM area: columnar dendrites and cellular dendrites (Fig. 15, c). The columnar dendrites structure

is usually seen around the FB, while the cellular dendrite structure is seen in the weld's middle area. The enlargement of the red box in Fig. 15, $c$ is the boundary between the two structures in WM shown in Fig. 15, $d$.

\section{Discussion of the experimental results}

Distortion occurs due to excessive heat during the welding process. During the cooling process, the material experiences shrinkage or expansion, resulting in attraction and making the material change shape. At a welding current of $120 \mathrm{~A}$, the material's heat is very high and when using four sequences (4 times welding process), the pipe will expand and shrink four times. This causes the highest distortion to occur at a welding current of $120 \mathrm{~A}$ with four sequences. The highest distortion occurred in the axial distortion at $445 \mu \mathrm{m}$ (Fig. 8,c). The welding with four sequences of type A welds produced the greatest deformation among other parameters [7].

The tensile strength depends on the depth of penetration and grain size. If the depth of penetration is sufficient with fine grain size, the ultimate tensile strength will be high and vice versa [2]. The depth of penetration depends on the welding current used in this study. Increasing the welding current can cause the temperature and heat input to increase so that the weld penetration deepens [17]. In orbital pipe welding, this will affect the weld's result, especially at the end of the weld, there will be over-penetration or perforated material (Fig. 12). This can be overcome by using a welding sequence to limit the temperature received by materials with the same heat input. In this study, the ultimate tensile strength of 662.58 $\mathrm{MPa}$ occurs in one sequence with a welding current of $120 \mathrm{~A}$ (Fig. 10,b). This is because the resulting specimen has deep weld penetration with a fine grain size in this parameter. In comparison, welding with two to four sequences will decrease tensile strength because the weld penetration is not deep with coarse grain size.

Microhardness depends on the size of the grains formed in each weld area (WM, HAZ and BM). Simultaneously, the grain size that is formed occurs due to temperature and heat input received by the material [18]. If the WM area has a fine grain size, it tends to have a high microhardness value. There is usually a decrease in the microhardness value in the $\mathrm{HAZ}$ area compared to the $\mathrm{WM}$ and $\mathrm{BM}$ areas. This is because the HAZ areas tend to have large grain sizes and coarse grain growth rates (Fig. 14, a). The highest microhardness value occurs in one sequence with horizontal and vertical distribution of $238.1 \mathrm{HV}$ and $242.8 \mathrm{HV}$, respectively (Fig. 11).

Macrostructural observations show the depth of penetration and width of the weld bead for each parameter variation. In orbital pipe welding, the penetration depth at each pipe position is influenced by the force of gravity $[2,19]$. The depth of penetration at the flat $\left(0^{\circ}\right)$ and overheat $\left(180^{\circ}\right)$ pipe positions is strongly influenced by the force of gravity. In addition, the temperature received by the material during the welding process also plays 
a role in the formation of weld penetration [20]. If the temperature received is high and almost reaches the material's melting point, there will be over-penetration or perforated material. Therefore, it is necessary to have a welding sequence to limit the temperature received by the material. However, this will also result in a less deep penetration in some pipe positions (Fig. 13).

Microstructure observations showed structural changes that occurred in the WM, HAZ and grain size areas. The growth rate of the structure is influenced by temperature and heat input received by the material [21]. In this study, the welding current and welding sequence used have a role in the structure's growth rate. Welding with one sequence, welding current of $110 \mathrm{~A}$ and pipe position of $180^{\circ}$ produces a finer grain size in the WM area (Fig. 14, $d$ ). This is due to the material's temperature and heat input so that a fine grain size structure is formed. Whereas in welding with four sequences, welding current of $110 \mathrm{~A}$ and pipe position of $180^{\circ}$ produces a structure with coarse and fine grain size in the WM area (Fig. 15, $d$ ). This is because the temperature and heat input received by the material is still insufficient to form a completely smooth structure in the WM area, so there is still a rough structure around FB.

The welding sequence method applied is a continuous welding sequence. When compared to the paper [7], the results show a similar trend. Welding in 4 sequences produces the greatest distortion. The tensile strength decreases for each additional welding sequence at all positions of the pipe under test.

This study only uses variations of the continuous welding sequence and welding current to determine the quality of the weld including distortion, mechanical properties and metallurgical observations. The continuous welding sequence on the pipe tends to increase the distortion and decrease the mechanical properties of the material. So that in the future research can be carried out using the jump welding sequence or the symmetric welding sequence on the pipe. In theory, it can reduce distortion, but the mechanical properties and metallurgical observations need to be investigated further.

\section{Conclusions}

1. Orbital pipe welding produces distortion (axial distortion, transverse distortion, ovality and taper) in the pipe. Increasing the welding current can increase the distortion, whereas adding a welding sequence to the pipe decreases the distortion, but if there are too many welding sequences, the distortion will rise. The greatest axial distortion and transverse distortion occurred at a welding current of $120 \mathrm{~A}$ with four sequences $445 \mu \mathrm{m}$ and $300 \mu \mathrm{m}$, respectively. Similarly, the ovality and taper occurred at the same welding parameters of $195 \mu \mathrm{m}$ and $275 \mu \mathrm{m}$, respectively.

2. Orbital pipe welding using more than one sequence tends to result in lower mechanical properties. The largest and smallest ultimate tensile strength (UTS) was $662.58 \mathrm{MPa}$ and $334.09 \mathrm{MPa}$, respectively. There was a decrease in UTS up to $51 \%$ against UTS base metal. Meanwhile, the microhardness value will also decrease if adding the welding sequence even with the same welding current and pipe position. In the horizontal distribution, the highest microhardness value in one sequence was $238.1 \mathrm{HV}$, and the smallest microhardness value in three sequences was $167.9 \mathrm{HV}$.

3. Orbital pipe welding results in different depths of penetration at each pipe position. Increasing the welding current can deepen penetration but adding the welding sequence can prevent penetration. The largest and smallest depth of penetration was $4.11 \mathrm{~mm}$ and $1.60 \mathrm{~mm}$, respectively. The heat-affected zone (HAZ) shows the austenite structure with a large grain size. The microstructure of the weld metal (WM) area with one sequence results in a finer cellular dendrites structure compared to four sequences. However, in four sequences, the structure is columnar dendrites and cellular dendrites.

\section{Acknowledgments}

This research is supported by the Master Program to Doctorate for Scholar Excellent (PMDSU) program of the Ministry of Research \& Technology and High Education (RISTEK DIKTI) 2018 with contract number 6265/UN2.R3.1/HKP05.00/2018.

References

1. Panji, M., Baskoro, A. S., Widyianto, A. (2019). Effect of Welding Current and Welding Speed on Weld Geometry and Distortion in TIG Welding of A36 Mild Steel Pipe with V-Groove Joint. IOP Conference Series: Materials Science and Engineering, 694, 012026. doi: https://doi.org/10.1088/1757-899x/694/1/012026

2. Eisazadeh, H., Haines, D. J., Torabizadeh, M. (2014). Effects of gravity on mechanical properties of GTA welded joints. Journal of Materials Processing Technology, 214 (5), 1136-1142. doi: https://doi.org/10.1016/j.jmatprotec.2014.01.002

3. Tseng, K.-H., Chuang, K.-J. (2012). Application of iron-based powders in tungsten inert gas welding for $17 \mathrm{Cr}-10 \mathrm{Ni}-2 \mathrm{Mo}$ alloys. Powder Technology, 228, 36-46. doi: https://doi.org/10.1016/j.powtec.2012.04.047

4. Tseng, K.-H., Chen, K.-L. (2012). Comparisons Between TiO2- and SiO2-Flux Assisted TIG Welding Processes. Journal of Nanoscience and Nanotechnology, 12 (8), 6359-6367. doi: https://doi.org/10.1166/jnn.2012.6419

5. Gill, S. S., Singh, J. (2013). Artificial intelligent modeling to predict tensile strength of inertia friction-welded pipe joints. The International Journal of Advanced Manufacturing Technology, 69 (9-12), 2001-2009. doi: https://doi.org/10.1007/s00170-013-5177-5

6. Tsai, C.-H., Hou, K.-H., Chuang, H.-T. (2006). Fuzzy control of pulsed GTA welds by using real-time root bead image feedback. Journal of Materials Processing Technology, 176 (1-3), 158-167. doi: https://doi.org/10.1016/j.jmatprotec.2006.02.027

7. Sattari-Far, I., Javadi, Y. (2008). Influence of welding sequence on welding distortions in pipes. International Journal of Pressure Vessels and Piping, 85 (4), 265-274. doi: https://doi.org/10.1016/j.ijpvp.2007.07.003

8. Harris, I. D. (2011). Welding advances in tube and pipe applications. Welding Journal, 90 (6), 58-63.

9. Lukkari, J. (2005). Orbital-TIG-a great way to join pipes. The ESAB Welding and Cutting Journal, 60 (01), 3-6. 
10. Wilsdorf, R., Pistor, R., Sixsmith, J. J., Jin, H. (2006). Welding aluminum pipe and tube with variable polarity. Welding Journal, 85 (4), 42-43.

11. Suwanda, T., Soenoko, R., Irawan, Y. S., Choiron, M. A. (2020). Temperature cycle analysis of A6061-AISI304 dissimilar metal continuous drive friction welding. Eastern-European Journal of Enterprise Technologies, 3 (12 (105)), 38-43. doi: https:// doi.org/10.15587/1729-4061.2020.203391

12. Okano, S., Mochizuki, M. (2017). Transient distortion behavior during TIG welding of thin steel plate. Journal of Materials Processing Technology, 241, 103-111. doi: https://doi.org/10.1016/j.jmatprotec.2016.11.006

13. Seyyedian Choobi, M., Haghpanahi, M., Sedighi, M. (2012). Effect of welding sequence and direction on angular distortions in buttwelded plates. The Journal of Strain Analysis for Engineering Design, 47 (1), 46-54. doi: https://doi.org/10.1177/0309324711425887

14. Yi, J., Zhang, J., Cao, S., Guo, P. (2019). Effect of welding sequence on residual stress and deformation of 6061-T6 aluminium alloy automobile component. Transactions of Nonferrous Metals Society of China, 29 (2), 287-295. doi: https://doi.org/10.1016/ s1003-6326(19)64938-1

15. Baskoro, A. S., Hidayat, R., Widyianto, A., Amat, M. A., Putra, D. U. (2020). Optimization of Gas Metal Arc Welding (GMAW) Parameters for Minimum Distortion of T Welded Joints of A36 Mild Steel by Taguchi Method. Materials Science Forum, 1000, 356-363. doi: https://doi.org/10.4028/www.scientific.net/msf.1000.356

16. Widyianto, A., Baskoro, A. S., Kiswanto, G. (2020). Effect of Pulse Currents on Weld Geometry and Angular Distortion in Pulsed GTAW of 304 Stainless Steel Butt Joint. International Journal of Automotive and Mechanical Engineering, 17 (1), 7687-7694. doi: https://doi.org/10.15282/ijame.17.1.2020.16.0571

17. Mistry, P. J. (2016). Effect of process parameters on bead geometry and shape relationship of gas metal arc weldments. International Journal of Advanced Research in Mechanical Engineering \& Technology, 2, 24-27.

18. Kumar, M. V., Balasubramanian, V. (2014). Microstructure and tensile properties of friction welded SUS 304HCu austenitic stainless steel tubes. International Journal of Pressure Vessels and Piping, 113, 25-31. doi: https://doi.org/10.1016/j.ijpvp.2013.11.005

19. Figueirôa, D. W., Pigozzo, I. O., e Silva, R. H. G., de Abreu Santos, T. F., Filho, S. L. U. (2017). Influence of welding position and parameters in orbital tig welding applied to low-carbon steel pipes. Welding International, 31 (8), 583-590. doi: https://doi.org/ 10.1080/09507116.2016.1218615

20. Qi, B. J., Yang, M. X., Cong, B. Q., Liu, F. J. (2013). The effect of arc behavior on weld geometry by high-frequency pulse GTAW process with 0Cr18Ni9Ti stainless steel. The International Journal of Advanced Manufacturing Technology, 66 (9-12), $1545-1553$. doi: https://doi.org/10.1007/s00170-012-4438-z

21. Casalino, G., Angelastro, A., Perulli, P., Casavola, C., Moramarco, V. (2018). Study on the fiber laser/TIG weldability of AISI 304 and AISI 410 dissimilar weld. Journal of Manufacturing Processes, 35, 216-225. doi: https://doi.org/10.1016/j.jmapro.2018.08.005 